\title{
PROJETO NOVOS TALENTOS
}

\author{
Adriano F. da Silva1; Danielle Y. Mizuno²; Eliohana de A. Peres²; Rones de S. \\ Santos $^{2}$; Paulo S. C. Ferreira²; Vinícius F. Esbell². \\ 1 Professor da Universidade Federal de Roraima. \\ ${ }_{2}^{2}$ Acadêmica(o) da Universidade Federal de Roraima.
}

PET Engenharia Civil UFRR, Universidade Federal de Roraima, Boa Vista, Roraima.

Palavras-chave: Extensão; Engenharia Civil; Processo Seletivo; Escolas;

\section{Introdução}

A atividade Novos Talentos, organizada pelo Grupo PET Engenharia Civil da Universidade Federal de Roraima em escolas públicas do Estado de Roraima desde 2017, busca divulgar os métodos de ingresso na universidade, os meios de auxílio financeiro oferecidos pela mesma, os processos sociais e educacionais de vivência universitária, assim como esclarecer o funcionamento do curso e explanar pontos cruciais da vida profissional de um engenheiro.

Em 2017, o projeto alcançou 577 alunos do Ensino Médio de 02 (duas) escolas públicas e 01 (uma) particular. Em 2018, o foco deu-se nas escolas públicas, tendo sido alcançado um público de 469 alunos, tendo atendido 04 (quatro) escolas públicas estaduais em Boa Vista, capital de Roraima e 01 (uma) escola pública militarizada localizada no município do Bonfim, a $120 \mathrm{~km}$ da capital. As escolas atendidas na capital são de diferentes bairros, atendendo alunos de diversas condições sociais.

O projeto baseou-se em diversos fatores que bloqueiam o desenvolvimento do curso, assim como a entrada de alunos na Universidade. Seguindo isto, analisouse que com o aumento progressivo do número de vagas no ensino superior brasileiro, surgiu a necessidade de desenvolvimento de estratégias de marketing 
educacional para que se despertasse 0 interesse dos alunos para as universidades públicas. Neste viés, obteve-se um dos pontos de partida deste projeto, ao observar-se que a dificuldade da disseminação da informação de processos seletivos é um obstáculo intrínseco ao marketing educacional (BRONNEMANN; SILVIERA, 2003).

Esta situação ainda é agravada quando se estudam alunos de escolas públicas, os quais têm o ensino superior como uma realidade distante (ALVARENGA et al, 2011). Neste sentido, um dos caminhos a ser tomado é o do desenvolvimento de novas atividades de extensão universitária, as quais trazem à universidade o foco no atendimento à comunidade frente a sua qualidade de ensino e nível de inserção de profissionais no mercado (NUNES et al, 2008).

Ademais, as dificuldades financeiras e inerentes ao próprio curso levam ao aumento da taxa de evasão do curso, sendo que por muitas vezes devem-se ao desconhecimento por parte dos alunos das bolsas e auxílios oferecidos. Neste sentido, o projeto busca trazer informação aos estudantes mesmo antes do seu ingresso na universidade, seja qual for a carreira escolhida pelos mesmos.

\section{Metodologia}

Com o propósito de levar aos alunos de escolas públicas informações sobre o curso de Engenharia Civil, os alunos do grupo PET Engenharia Civil UFRR fizeram visitas às escolas e apresentaram, utilizando um projetor, o projeto Novos Talentos.

O projeto se iniciava em uma reunião do grupo, onde eram escolhidas as escolas a serem contempladas, por sugestões dos petianos. Em seguida, era escolhido o participante do grupo que ficaria responsável pelo contato com a escola e coletar informações sobre quantidade de alunos, se possui auditório disponível, projetor e sistema de som.

Concluída essa parte inicial, se definia a data que a administração da escola julgasse mais conveniente para a realização do evento. Para melhor informar aos alunos das escolas sobre o grupo PET, o projeto Novos Talentos e dar informações importantes sobre os processos seletivos eram impressos panfletos em quantidade suficiente para entregar a todos os alunos.

A apresentação foi previamente montada pelo grupo PET Engenharia Civil UFRR e dá espaço para serem comentados assuntos como a quantidade de 
vagas no Curso de Engenharia Civil da UFRR, as formas de ingresso, notas de corte, auxílios e bolsas oferecidos pela Universidade Federal além da vida profissional do Engenheiro Civil, assunto que sempre desperta bastante curiosidade e é apresentado pelo professor tutor do PET e pelos petianos. Foi também desenvolvido pelos petianos, um folder sobre o projeto, o qual foi impresso e entregue a cada aluno participante, na ocasião das palestras. Além disso divulgou-se a ação através de material impresso e no site do Grupo PET em questão (ufrr.br/petengcivil). A figura 1 exibe uma atividade do projeto no município de Bonfim - RR.

Figura 1:Apresentação do projeto Novos Talentos na Escola militarizada Aldébaro José Alcântara, em Bonfim - RR

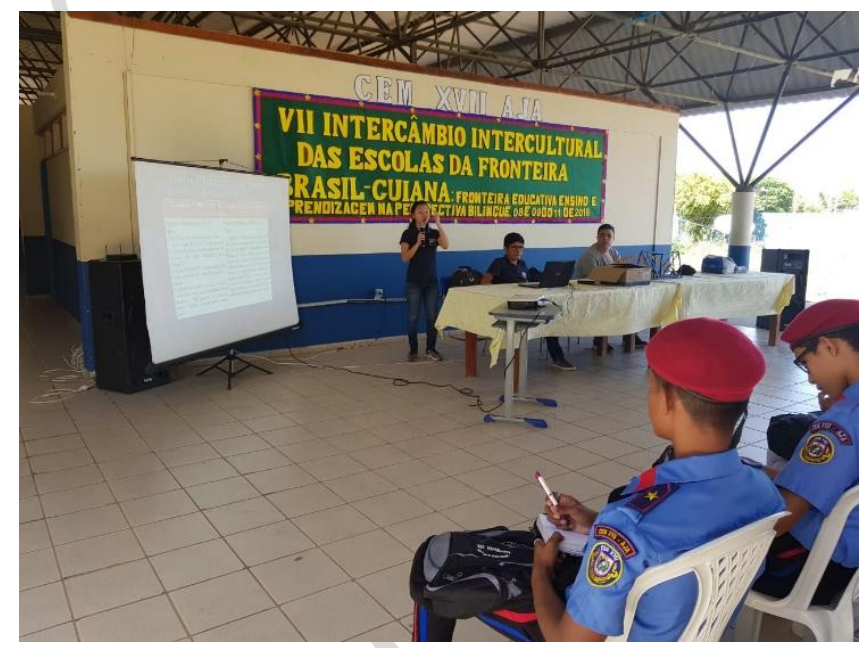

Fonte: PET Engenharia Civil UFRR, 2018

No projeto realizado no município de Bonfim, a 120 km da capital Boa Vista, para despertar ainda mais o interesse dos alunos o grupo PET, fez um concurso de pontes de palito de picolé. Para realizar essa ação foi necessário que quatro petianos fossem até o município uma semana antes para explicar sobre 0 processo de montagem e avaliação das pontes e deixar o material para a construção delas. Na semana seguinte foi levado o equipamento para o rompimento das pontes feitas e a premiação de todos os alunos que participaram.

\section{Resultados e discussão}

Ao final do projeto, foram atendidos um total de 1046 alunos, sendo 07 escolas atendidas em Boa Vista (03 em 2017 e 04 em 2018) e 01 no município de Bonfim- 
$R R$, no interior do estado, onde todos os participantes eram alunos do Ensino Médio e do Ensino Fundamental. A apresentação do curso de Engenharia Civil, levando em consideração a vida profissional e acadêmica, os processos de entrada na UFRR, assim como, os auxílios e bolsas oferecidas pela mesma, foi realizada conforme o programado, onde todas as áreas da engenharia civil foram explanadas durante a apresentação de forma clara para os alunos. Observou-se que a maioria dos participantes não possuíam conhecimento das várias áreas de atuação do profissional, assim como os vários ramos da Engenharia Civil e sua importância para o crescimento urbano e organização da sociedade, pensavam apenas que a atuação do Engenheiro Civil era construir prédios e casas. No município de Bonfim, onde foi realizado, além da palestra uma dinâmica em que construíram pontes de palitos de picolé, os alunos puderam entrar em contato com os desafios enfrentados pelos engenheiros, podendo assim, perceberem de forma mais visível a sua real vocação profissional. Notouse, no fim da palestra, um maior interesse dos alunos em relação ao curso no local onde foi realizado a dinâmica. As figuras 2,3 e 4 apresentam 0 desenvolvimento do projeto Novos Talentos.

Figura 2:Palestra pelo Tutor do PET na Escola Estadual Maria das Dores Brasil.

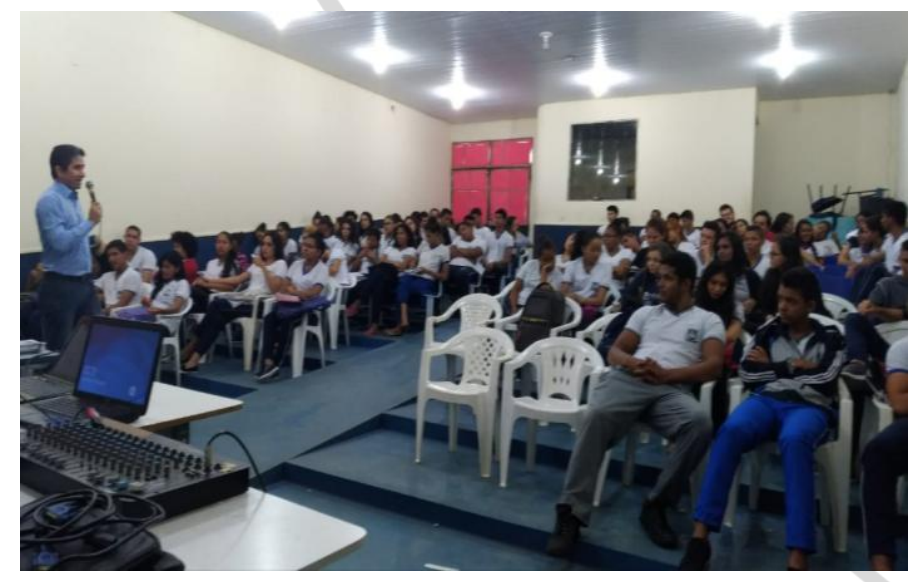

Fonte: PET Engenharia Civil - UFRR, 2018. 
Figura 3: Palestra por Petianos na Escola Estadual Professora Vanda da Silva Pinto.

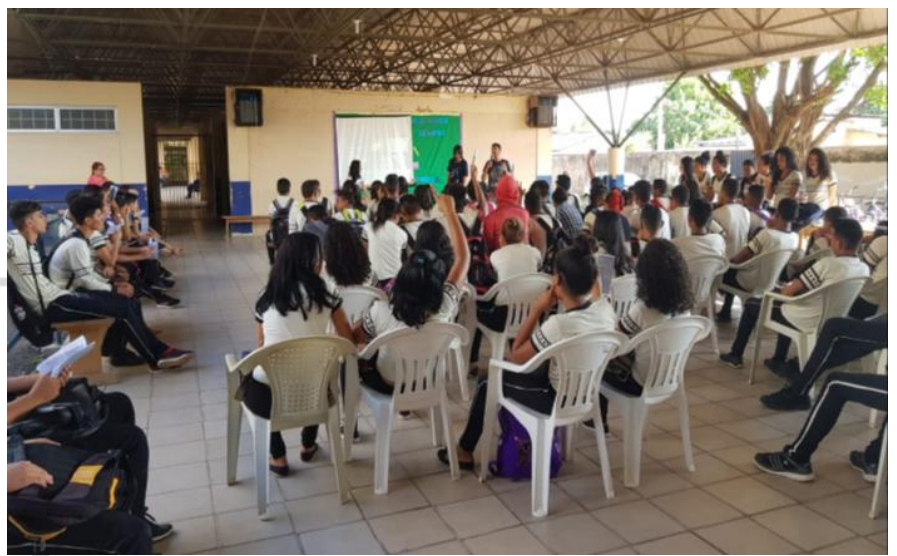

Fonte: PET Engenharia Civil - UFRR, 2018.

Figura 4: Dinâmica realizada no Colégio Estadual Militarizado XVII Aldébaro José Alcântara localizado na cidade de Bonfim - RR.

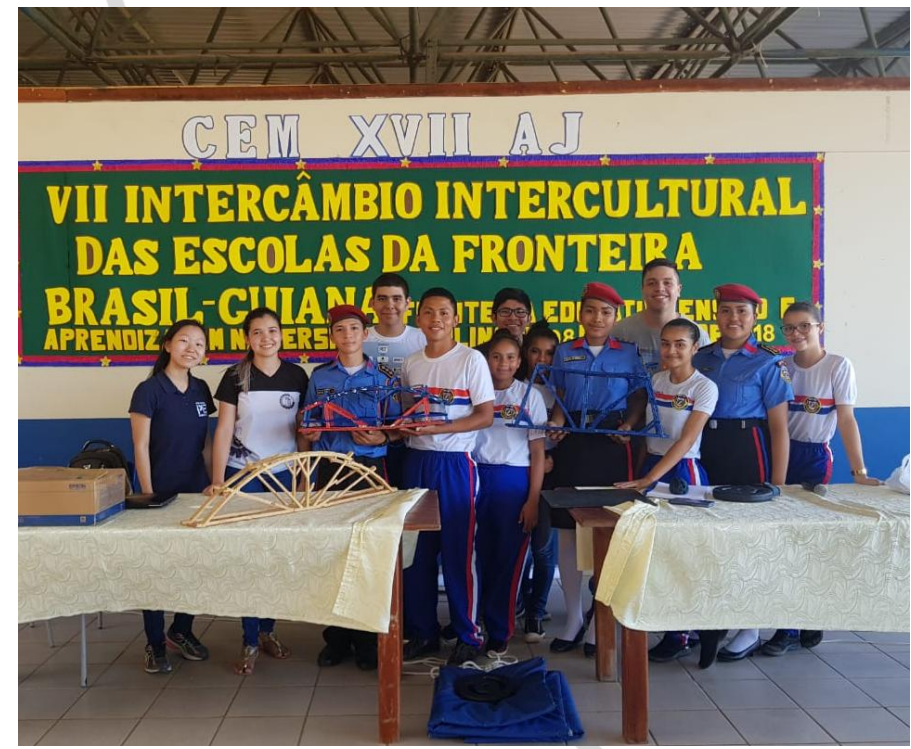

Fonte: PET Engenharia Civil - UFRR, 2018.

\section{Conclusão}

A ação de extensão Novos Talentos obteve um considerável alcance de escolas e alunos, desde o Ensino Fundamental ao Ensino Médio, contando com a participação de um total de 1046 aluno. A prioridade de abrangência de escolas públicas pela ação teve sua importância reafirmada através da realidade compartilhada pelos estudantes das mesmas. Observou-se que, em geral, poucos alunos planejavam ingressar no Ensino Superior, sendo relevante a divulgação de informações da Universidade Federal de Roraima e do curso de 
Engenharia Civil, como auxílios fornecidos e áreas de atuação para profissionais da Engenharia.

O engajamento dos alunos durante as palestras e atividades promovidas, foi positivo de tal forma que se notou a importância de se dar continuidade ao projeto de extensão.

\section{Referências}

ALVARENGA, C. F.; SALES, A. P.; COSTA, A. D.; DA COSTA, M. D.; VERONEZE, R. B.; SANTOS, T. L. B. Desafios do ensino superior para estudantes de escola pública: um estudo na UFLA. Revista Pensamento Contemporâneo em Administração. Lavras, 2011.

BRONNEMANN, M. R.; SILVEIRA, A. Marketing em instituições de ensino superior: a promoção do processo seletivo. FURB. Blumenal, 2003.

FIORANI, L. A.; LOPES, M. P. G.; NAKAO, O. S. Evasão na engenharia civil da escola politécnica da USP: o que pensam os alunos e professores. COBENGE. Blumenau, 2011.

NUNES, G. T.; LANZER, E. A.; SERRA, F. R.; FERREIRA, M. P. Emergência do marketing nas instituições de ensino superior: um estudo exploratório. Revista Análise. Porto Alegre, 2008. 